\title{
Retraction Note to: Effects of multi-support misalignments on hole straightness predict model in deep hole drilling
}

\author{
Liang $\mathrm{Li}^{1,2}(\mathrm{C}) \cdot \mathrm{Hu} \mathrm{Xue}^{1} \cdot$ Dongya $\mathrm{Li}^{3} \cdot \mathrm{Ning} \mathrm{He}^{2}$
}

Published online: 22 July 2020

(c) The Brazilian Society of Mechanical Sciences and Engineering 2020

\section{Retraction Note to: Journal of the Brazilian Society of Mechanical Sciences and Engineering (2020) 42:219 https://doi.org/10.1007/s40430-020-02302-9}

The Editors-in-Chief have retracted this article [1] due to significant similarities with a thesis by another researcher [2].

\section{References}

1. Li L, Xue H, Li D et al (2020) Effects of multi-support misalignments on hole straightness predict model in deep hole drilling. $\mathrm{J}$ Braz Soc Mech Sci Eng 42:219. https://doi.org/10.1007/s4043 0-020-02302-9

The original article can be found online at https://doi.org/10.1007/ s40430-020-02302-9.

\section{Liang $\mathrm{Li}$}

jzlliang@163.com

1 College of Mechanical Engineering, Yancheng Institute of Technology, Yancheng 224051,

People's Republic of China

2 College of Mechanical and Electrical Engineering, Nanjing University of Aeronautics and Astronautics, Nanjing 210016, People's Republic of China

3 Department of Mechanical Engineering, Technical University of Denmark, 2800 Kgs. Lyngby, Denmark
2. Chaudhari A (2016) A study on straightness control in deep hole drilling of Inconel-718. Ph.D. thesis, National University of Singapore

Publisher's Note Springer Nature remains neutral with regard to jurisdictional claims in published maps and institutional affiliations. 